\title{
O PÃO DOS POBRES E O TERCEIRO SETOR
}

Leandro R. Pinheiro*

SINTESE - Objetiva-se apresentar, aqui, alguns elementos da trajetória de integração da escola Pão dos Pobres com a comunidade portoalegrense, sobretudo no que concerne à manutenção de suas bases materiais, de modo a levantar alguns indicios iniciais da inserção desta instituição ao hoje denominado terceiro setor, fenômeno vinculado à promoção de solidariedade social e cidadania.

PALAVRAS-CHAVE - "terceiro setor", solidariedade social e cidadania.
ABSTRACT - We aim to show here some elements of the trajectory of integration of the school Pão dos Pobres with the community of Porto Alegre, especially conceming the maintenance of its material bases. With this we intend to raise some initial hints of the insertion of this institution to the nowadays called third sector, a phenomenon related to the promotion of social solidarity and citizenship.

KEY WORDS - third sector, social solidarity and citizenship.

"Precisamos agora continuar o trabalho de formação de uma cultura solidária na sociedade brasileira, apoiando as organizações sociais", dando "ao setor a visibilidade e a confiança da população", ${ }^{1}$ afirma Maria Elena Johanpeter, representante de uma organização sem fins lucrativos, num discurso que tem sido freqüente na imprensa escrita brasileira atual. Trata-se da valorização de iniciativas oriundas da sociedade civil, voltadas ao desenvolvimento de solidariedade social e cidadania e ao combate à exclusão social, cuja denominação mais utilizada tem sido a de terceiro setor. No entanto, tais propósitos têm um passado próximo na história construída por um de seus membros: a Pia União do Pão dos Pobres de Santo Antônio, de Porto Alegre. E é a partir desta constatação que se realizará uma retrospectiva da relação estabelecida entre esta instituição e a comunidade porto-alegrense, buscando evidenciar como o Pão dos Pobres articula-se com os vários agentes sociais na manutenção de suas bases materiais ao longo do tempo, esboçando, inclusive, alguns indícios do que se considera uma possível revitalização desta obra perante a sociedade, cuja origem, então, estaria vinculada ao crescimento do chamado terceiro setor.

* Graduando do $7^{\circ}$ nivel do Curso de Ciências Sociais da PuCRs e bolsista de iniciação científica da Fundação de Amparo à Pesquisa do Rio Grande do Sul (FAPERGs) junto à linha de pesquisa Formação, Trabalho, Instituição.

1 "Uma nova era para o voluntariado". Zero Hora, Porto Alegre, 13 mar. 1998, p. 19.

\begin{tabular}{|l|l|l|l|l|l|} 
VERITAS & Porto Alegre & v. 43 & $\mathrm{n}^{\mathrm{9}}$ especial & Dezembro 1998 & p. 35-39
\end{tabular}




\section{1 - Pão dos Pobres, benfeitores e solidariedade social}

Princípio do século XX, a República instaurada e, com ela, constituída a noção de cidadão, cuja "principal virtude" seria "o gosto pelo trabalho" e o "hábito da poupança" (Chalhoub, 1995, p. 6). Em Porto Alegre, especificamente, o processo de industrialização e a imigração se aprofundavam, estabelecendo patamares elevados de crescimento e, concomitantemente, aumento da população carente. As escolas de ofício católicas (e, entre elas, o Pão dos Pobres) assumiriam a responsabilidade de assistir à população desprivilegiada e formar o cidadão e trabalhador que o período histórico exigia, atividade endossada pela política positivista do governo estadual de então que postulava a "incorporação do proletariado à sociedade moderna" (Desaulniers, 1997, p. 319), e pela encíclica Rerum Novarum, ${ }^{2}$ de 1891.

O Pão dos Pobres, em 1916, tornava-se orfanato para meninos carentes em regime de internato, voltando-se, sob a direção dos irmãos lassalistas, à formação das classes populares reivindicada pela sociedade vigente (Desaulniers, 1995, p. 235-236). Em relação intensa com a comunidade de Porto Alegre, o orfanotrófio sofreu modificações e ampliações em sua estrutura no intuito de corresponder às demandas da população ao seu redor que, por seu turno, teve papel fundamental na manutenção de suas bases materiais.

Os benfeitores, como são chamados até hoje os colaboradores da instituição, eram, em geral, membros da elite social: homens de negócio da indústria, comércio, administração pública e representantes oficiais das Armas, convocados a, mais do que fazer doações, comprometer-se com a causa do Pão dos Pobres. Neste sentido, a década de vinte é um período exemplar do desenvolvimento de solidariedade social, pois, na medida que se idealizou a construção do Liceu de Artes e Ofício (inaugurado em 1930) e "não tendo, porém, a instituição recursos próprios para levantar o desejado edifício, ficou estabelecido convidar-se um certo número de distintas senhoras e senhores para, com o seu prestígio no meio social e na qualidade de amigos e benfeitores do Pão dos Pobres, adquirirem os recursos necessários". ${ }^{3}$ Essa comissão e outras formadas para a sustentação posterior da obra organizaram torneios, chás beneficentes, rifas, festas, concertos e arrecadaram donativos, numa ação que consolidara a iniciativa do Pão dos Pobres em meio aos agentes sociais da capital gaúcha. No entanto, houve, também, algumas atividades de ocorrência periódica, como a festa de São Roque, as comemorações de Natal, a institucionalização de madrinhas de internos e os cultos a Santo Antônio, padroeiro das coisas perdidas, que atraíra seus devotos no auxílio da restituição da integridade física e moral dos jovens carentes, esses seres "perdidos" (Desaulniers, 1995, p. 238).

Além da moral religiosa, o Pão dos Pobres utilizava outros artifícios para despertar o interesse junto aos demais agentes sociais de Porto Alegre e garantir sua existência. Eram freqüentes os apelos à solidariedade e caridade, "a mais santa

2 Considerada a "encíclica dos trabalhadores", a Rerum Novarum visava voltar a Igreja para as classes populares e, por conseguinte, ampliar sua presença na sociedade (Desaulniers, 1995, p. 235).

3 Boletim do Pão dos Pobres, ano 26, n. 1, dez. 1924 - jan./fev. 1925, p. 10. 
das virtudes", 4 através da imprensa local e, principalmente, do Boletim Pão dos Pobres, criado em 1898 pela referida entidade e publicado até 1967. Este fora elaborado, justamente, para propalar os valores cristãos e as atividades da obra e, a partir daí, conquistar colaboradores (Desaulniers, 1995, p. 239).

Outro elemento que promovia a integração com a comunidade era a correspondência entre esta e o serviço prestado pelo Pão dos Pobres, que visava constituir "o homem integral, privilegiando a moralização e a sistematização de práticas e representações religiosas, através de uma educação intelectual, profissional, física e social" (Desaulniers, 1997, p. 325), fazendo do órfão o cidadão da época. E esses cidadãos em formação eram exibidos ostensivamente em visitas a autoridades com grupos de internos, por convites para visitas à instituição, na apresentação dos órfãos na igreja, dentre outras atividades.

Permanece a acentuada articulação entre a escola e demais campos sociais até 1970 aproximadamente, quando o discurso religioso já não agregava mais a população com a mesma intensidade e a própria assistência social privada e o apelo pela solidariedade que continha fora suprimida pela institucionalização mais severa do Estado de bem-estar social brasileiro, durante o regime militar.

\section{2 - Solidariedade x exchusão, uma nova etapa}

A expressão terceiro setor é usada para designar um "conjunto de organizações e iniciativas privadas que visam à produção de bens e serviços públicos" (Fernandes, 1994, p. 21). É uma categoria ampla, sem dúvida, que almeja demarcar, sobretudo, a autonomia da sociedade civil frente ao Estado. Pode-se dizer que, na América Latina, teria iniciado a partir do surgimento de movimentos sociais e organizações não governamentais, cujo propósito seria criar alternativas de representatividade política nos contextos de regime militar da década de setenta, quando os meios tradicionais (partidos e sindicatos) estavam debilitados. Porém, com os processos de redemocratização, relativiza-se a orientação política de tais iniciativas. "É nesta fase que começa a se falar de um terceiro setor, além do mercado e do Estado, formado por organizações dos dois blocos": as iniciativas modernas, alternativas e voltadas para o desenvolvimento social sustentável, por um lado, e as entidades ligadas à caridade e beneficência, tidas como conservadoras, por outro (Thompson, 1997, p. 45). Passa então a ser valorizada cada vez mais a funcionalidade dessas iniciativas privadas para a economia (Menescal, 1996, p. 121), sendo que a ênfase neste aspecto (observado, principalmente, no discurso de apoio à solidariedade, corrente na imprensa ${ }^{5}$ ) aumenta com a politica de "redução" do Estado e a otimização do mercado.

4 Boletim do Pão dos Pobres, ano 26, n. 1, dez. 1924 - jan./fev. 1925, p. 7.

5 Dentre as fontes usadas para tais constatações estão, principalmente: os jornais Zero Hora e Folha de São Paulo, no periodo de maio/1997 a junho/1998; material coletado no II Encontro Internacional de Fundações, realizado na PUCRS, nos dias 1 e 2 de outubro/1997; e as Homepages: www. gife.org.br e www. kanitz.com.br. 


\section{1 -O Pão dos Pobres e o "terceiro setor"}

Atualmente, dado o novo contexto de valorização da solidariedade social e de sua funcionalidade para o mercado, no combate à exclusão, é possível evidenciar indícios de revitalização da interação do Pão dos Pobres junto aos demais agentes sociais. ${ }^{6}$ Prestando o mesmo serviço social (formação profissional de jovens carentes), a instituição mantém, ainda hoje, as doações espontâneas dos benfeitores, perfazendo, aproximadamente, um terço do seu orçamento e possibilitando, inclusive, a emissão de carnês, tendo em vista a regularidade com que acontece. ${ }^{7}$

Embora o capital religioso não atraia 0 interesse da população como antigamente, limitando ou redirecionando as alternativas de bases materiais ao Pão dos Pobres, este tem encontrado, recentemente, novas parcerias (e projetos) capazes de manter, e até ampliar, a sua iniciativa formativa. Através da atual dinamização da sociedade civil e flexibilização das atividades do Estado, esta escola tem usufruido, por exemplo, das atividades do Comunidade Solidária, sendo "contemplados [este ano] com cinco cursos", como menciona o diretor geral da entidade. Também tem realizado cursos para jovens em parceria com a Fundação Maurício Sirotsky Sobrinho e, além disso, trabalhado junto à Secretaria do Trabalho e Ação Social, "servindo de interface entre empresa (pública) e a instituição que assume o aspecto didático-pedagógico", ${ }^{8}$ para garantir quatro horas de trabalho-estágio remunerado a menores carentes regularmente matriculados. Da mesma forma, é importante mencionar a adesão do Pão dos Pobres à recente Associação RioGrandense de Fundações, embora, segundo os representantes da escola, esta instituição ainda não possua expressão frente à sociedade.

$O$ outro elemento que desperta a atenção da comunidade, e talvez explique o êxito nas parcerias citadas e a permanência (vamos dizer, solidária) das doações espontâneas, é o serviço social prestado pelo Pão dos Pobres, os resultados que continua apresentando, concretizados nos alunos formados, cuja inserção no mercado de trabalho, de acordo com o diretor da instituição, é absoluta. Estaria em questão, aqui, também o respaldo moral conquistado por intermédio da construção de cidadania, em função da chance de inserção ao mercado concedida a indivíduos carentes, entendida por Léo Voigt (diretor da Fundação Maurício Sirotsky Sobrinho) como a forma de combater a exclusão social, de ter os "direitos cidadãos garantidos"," ou seja, ter a possibilidade de "vida digna, condições de moradia, trabalho, participação, proteção à saúde, acesso à escola, informação, lazer" (Voigt, 1998, p. 66), construindo o que Vieira cita como a cidadania descrita por T. H. Marshal, formada por direitos civis e politicos (liberdade, igualdade, propriedade, direito à vida, segurança, etc.) e direitos sociais (trabalho, saúde, educação, aposentadoria, etc.) (Vieira, 1997, p. 22-23).

6 As informações sobre a situação recente desta escola foram coletadas em entrevistas realizadas com o diretor geral em novembro de 1997 e junho de 1998. Trata-se de uma investigação em curso, cujos resultados terão de ser, provavelmente, reavaliados. O Pão dos Pobres possui, também, como fonte de recursos uma escola particular, uma livraria e os serviços prestados pelas oficinas ao mercado (como já faziam no passado). Depoimento do diretor geral da entidade na entrevista realizada em junho/1998.

9 Uma função assumida e divulgada pelo "terceiro setor". 


\section{3 - Considerações finais}

Efetuada esta primeira análise, o que se constata são indicadores de uma rearticulação entre o Pão dos Pobres e os demais agentes da sociedade, com uma reorientação na obtenção de recursos materiais entre as diferentes esferas sociais. As bases materiais, outrora mantidas através da conversão do capital religioso, por meio das convocações à solidariedade e dos resultados demonstrados à comunidade e ao mercado, são angariadas, hoje, em nome da mesma profissionalização prestada, ao menos no que concerne às parcerias abertas pela flexibilização das atividades do Estado e pelo atual contexto de promoção de iniciativas da sociedade civil que combatam as deficiências sociais. Ademais, o crescimento do terceiro setor e a valorização da solidariedade e da cidadania que este traz consigo podem ampliar as fontes de recursos humanos, concretizadas na forma de voluntariado. $O$ Pão dos Pobres tem mantido colaboradores, na forma de benfeitores, em função, provavelmente, do capital moral acumulado (viabilizado pelo serviço social que realiza), logo, a legitimação do trabalho voluntário e a instigação da solidariedade social pelo terceiro setor, podem significar novas adesões ao empreendimento em questão.

\section{Referências bỉbliográficas}

CHALHOUB, Sidney. “Trabalhadores: classe perigosa”, Coleção Trabalhadores, São Paulo, 1995, p. 122.

DESAULNIERS, Julieta B. R. "A Instituição: um lugar de produção social”. Veritas, Porto Alegre, v. 40, n 158 , jun. 1995, p. $235-242$.

__ _. . "Formar o Cidadão: uma proposta da escola católica". Veritas, Porto Alegre, v. 42, n. 2, jun. 1997, p. 317-331.

FERNANDES, Rubem C. Privado porém público: o terceiro setor na América Latina. Rio de Janeiro: Relume-Dumará, 1994, $156 \mathrm{p}$.

MENESCAL, Andréa K. "História e gẽnese das organizações não-governamentais". In: GONÇALVES, Hebe S. (org.). Organizações não governamentais: solução ou problema? São Paulo: Estação Liberdade, 1996, p. 21-38/111-126.

THOMPSON, Andrés A. "Do compromisso à eficiência? Os caminhos do terceiro setor na América Latina”. In: IOSCHPE, Evelyn B. $3^{\circ}$ setor: desenvolvimento social sustentado. Rio de Janeiro: Paz e Terra, 1997, p. 41-48.

VIEIRA, Liszt. Cidadania e globalização. Rio de Janeiro: Record, 1997, p. 1-68.

VOIGT, Léo. "O papel do terceiro setor no final do século". In: BARRII, Heloisa de Carvalho (org.). A pesquisa em Serviço Social e nas áreas humano-sociais. Porto Alegre: EDIPUCRS, 1998, p. 61-72. 